\title{
HUBUNGAN PENGETAHUAN DENGAN SIKAP DAN HIGIENE PERORANGAN (PERSONAL HYGIENE) PENJAMAH MAKANAN PADA PENYELENGGARAAN MAKANAN ASRAMA PUTRI
}

\author{
Edinda Ayu Miranti ${ }^{1}$, Annis Catur Adi ${ }^{2}$ \\ ${ }^{1}$ Program Studi Ilmu Gizi, Fakultas Kesehatan Masyarakat, Universitas Airlangga, Surabaya \\ ${ }^{2}$ Departemen Gizi Kesehatan, Fakultas Kessehatan Masyarakat, Universitas Airlangga, Surabaya \\ Email: edindaayumiranti@gmail.com
}

\begin{abstract}
ABSTRAK
Penyelenggaraan makanan pada asrama siswa sebaiknya memperhatikan prinsip higiene dan sanitasi yang telah ditetapkan. Salah satu faktor yang mendukung prinsip higiene dan sanitasi penyelenggaraan makanan adalah kebersihan diri penjamah makanan agar mencegah kontaminasi pada makanan. Pengetahuan dan sikap penjamah makanan dapat memengaruhi perilaku kebersihan diri penjamah makanan. Tujuan penelitian ini adalah menganalisis hubungan pengetahuan dengan sikap dan higiene perorangan penjamah makanan pada penyelenggaraan makanan asrama putri. Penelitian ini adalah penelitian observasional dengan desain cross sectional. Sampel adalah seluruh penjamah makanan pada penyelenggaraan makanan asrama putri Al Izzah Kota Batu dan Ar Rohmah Malang yaitu 20 responden dengan metode sampling jenuh (populasi < 30). Hubungan antar variabel menggunakan uji statistik Rank Spearman. Hasil penelitian menunjukkan bahwa sebagian besar pengetahuan $(55,0 \%)$ dan sikap $(65,0 \%)$ adalah baik, sedangkan higiene perorangan masuk kategori sedang (85,0\%). Hasil uji hubungan menunjukkan bahwa tidak ada hubungan antara pengetahuan dengan sikap $(\mathrm{p}>0,10)$, namun terdapat hubungan antara pengetahuan dengan higiene perorangan $(\mathrm{p}<0,10)$. Kesimpulan pada penelitian ini adalah pengetahuan bukan merupakan satu-satunya faktor yang dapat memengaruhi sikap, namun pengetahuan adalah salah satu faktor yang dapat memengaruhi higiene perorangan penjamah makanan. Penyelenggara Makan Asrama Putri perlu meningkatkan pengawasan dan memberikan pelatihan mengenai higiene dan sanitasi kepada penjamah makanan.
\end{abstract}

Kata kunci: higiene perorangan, pengetahuan, penyelenggaraan makanan, sikap

\section{ABSTRACT}

Food service provider of student dormitory have to pay attention to the principles of hygiene and sanitation. One of factors that support the principles of hygiene and sanitation on food service establishment is personal hygiene of food handlers, in order to prevent contamination of food. Knowledge and attitude of food handlers can affect the personal hygiene behavior of food handlers. The purpose of this study was to analyze correlation of knowledge with attitude and personal hygiene of food handlers in food service provider of female student dormitory. This study was an observational study with cross sectional design. The sample of this study was all food handlers at food service provider of female student dormitory Al Izzah Batu City and Ar Rohmah and it was twenty respondents with saturated sampling method (population < 30). The analysis technique used in this study was Spearman's Rank test. The results showed that most food handlers have good knowledge (55.0\%) and attitude (65.0\%), meanwhile personal hygiene were moderate (85.0\%). The test results showed that there was no correlation between knowledge and attitude $(p>0.10)$, but there was a correlation between knowledge and personal hygiene ( $p>0.10)$. This study concluded that knowledge is not the only factor that can influence the attitude, but knowledge is one of factors that may affect personal hygiene of food handlers. Food organizer of female student dormitory needs to improve the supervision and give hygiene and sanitation training for food handlers.

Keywords: personal hygiene, knowledge, food service, attitude 


\section{PENDAHULUAN}

Penyelenggaraan makanan asrama siswa merupakan penyelenggaraan makanan yang diadakan oleh asrama pada suatu sekolah tertentu. Penyelenggaraan makanan pada asrama siswa sebaiknya juga memperhatikan prinsip penyelenggaraan makanan yang telah ditetapkan dan disesuaikan dengan kebutuhan gizi penghuni asrama agar dapat menjaga status gizi, meningkatkan status kesehatan dan diharapkan dapat berdampak pada tingkat kehadiran siswa serta meningkatkan prestasi belajar siswa.

Menurut Fatmawati, dkk. (2013), salah satu prinsip dasar penyelenggaraan makanan institusi adalah penyelenggaraan makanan yang menerapkan higiene dan sanitasi sesuai ketentuan yang berlaku. Salah satu faktor yang mendukung prinsip higiene dan sanitasi penyelenggaraan makanan adalah faktor kebersihan penjamah makanan atau higiene perorangan. Higiene perorangan merupakan perilaku bersih, aman dan sehat penjamah makanan untuk mencegah terjadinya kontaminasi pada makanan mulai dari persiapan bahan makanan sampai penyajian makanan. Beberapa prosedur penting bagi penjamah makanan, yaitu cuci tangan sebelum dan sesudah memegang bahan makanan, memakai alat pelindung diri yang lengkap dan kebersihan serta kesehatan diri.

Menurut Badan POM RI (2011), Kejadian Luar Biasa (KLB) keracunan makanan selama tahun 2011 tercatat $128 \mathrm{kejadian} / \mathrm{kasus}$ yang berasal dari 25 provinsi. Dilaporkan kasus KLB keracunan pangan sebanyak 6.901 orang sakit. Pada bulan Juli-September 2015, keracunan akibat makanan salah satunya disebabkan oleh makanan dari jasaboga, yaitu sebanyak 9 insiden keracunan dengan jumlah korban 546 orang.

Salah satu sumber penularan penyakit dan penyebab terjadinya keracunan makanan, yaitu makanan dan minuman yang terkontaminasi bahan berbahaya dan tidak memenuhi syarat higiene (Cahyaningsih, dkk., 2009). Perilaku higiene penjamah makanan tidak terlepas dari sikap dan pengetahuan mengenai higiene dan sanitasi makanan. Pengetahuan, sikap dan higiene perorangan penjamah makanan sangat penting dalam penyelenggaraan makanan agar makanan yang dihasilkan terhindar dari kontaminasi.
Berdasarkan hasil penelitian Budiyono, dkk. (2008), sebagian besar tingkat pengetahuan penjamah makanan mengenai higiene dan sanitasi masuk kategori kurang. Purwaningtyas (2013) juga menyatakan praktek higiene penjamah makanan pada penyelenggaraan makanan Pondok Pesantren sebagian besar masuk kategori buruk dan menurut Meikawati, dkk. (2010), sebagian besar penjamah makanan bersikap tidak mendukung mengenai higiene dan sanitasi. Menurut hasil penelitian Erruliya (2008), terdapat hubungan antara pengetahuan dengan sikap higiene dan sanitasi penjamah makanan serta ada hubungan pula antara pengetahuan dengan praktek higiene penjamah makanan.

Penyelenggaraan makanan Asrama Putri Al Izzah dan Ar Rohmah mempunyai kesamaan, yaitu tidak ada kualifikasi pendidikan untuk penjamah makanan yang bekerja. Penjamah makanan yang bekerja merupakan para ibu yang dapat memasak dan tinggal tidak jauh dari wilayah kedua asrama tersebut. Oleh karena itu penelitian ini bertujuan untuk menganalisis hubungan pengetahuan dengan sikap dan higiene perorangan penjamah makanan pada penyelenggaraan makanan asrama putri.

\section{METODE}

Jenis penelitian ini merupakan penelitian observational dengan desain penelitian cross sectional. Penelitian dilaksanakan pada bulan Maret-Mei 2016 di Penyelenggaraan Makanan Asrama Putri Al Izzah Kota Batu dan Ar Rohmah Malang. Sampel pada penelitian ini adalah seluruh penjamah makanan penyelenggaraan makanan asrama putri Al Izzah dan Ar Rohmah dengan besar sampel adalah 22 responden. Teknik pengambilan sampel menggunakan sampling jenuh (populasi $<30$ ). Namun, pada saat penelitian, responden yang memenuhi kriteria berjumlah 20 responden, sedangkan 2 responden lainnya, yaitu 1 orang tidak bersedia menjadi responden dan 1 orang mengalami disable (tuna rungu).

Pengumpulan data karakteristik (umur, pendidikan terakhir, lama bekerja dan keikutsertaan pelatihan/penyuluhan), pengetahuan dan sikap responden mengenai higiene dan sanitasi penyelenggaraan makanan diperoleh dengan 
wawancara dengan kuesioner yang mengacu pada Permenkes RI No.1096/MENKES/PER/ $\mathrm{VI} / 2011$,sedangkan data mengenai higiene perorangan diperoleh melalui observasi selama melaksanakan kegiatan persiapan hingga pendistribusian makanan.

Data yang diperoleh dilakukan skoring kemudian diolah dan disajikan dalam bentuk tabel dan dianalisis deskriptif. Data mengenai uji hubungan dilakukan dengan uji statistik Rank Spearman dengan tingkat kepercayaan $90 \%(\alpha=0,10)$. Penelitian ini telah mendapatkan persetujuan etik dari Komisi Etik Penelitian Kesehatan Fakultas Kesehatan Masyarakat Universitas Airlangga dengan nomor 244-KEPK.

\section{HASIL DAN PEMBAHASAN}

Karakteristik penjamah makanan sebagian besar masuk dalam kategori umur produktif sebelum pralansia, pendidikan terakhir SD, lama masa kerja $\geq 3$ tahun dan tidak pernah mengikuti pelatihan/penyuluhan mengenai higiene dan sanitasi penyelenggaraan makanan. Karakteristik penjamah makanan dapat dilihat pada Tabel 1.

Umur. Pada tabel 1 menunjukkan bahwa sebagian besar penjamah makanan masuk dalam kategori produktif sebelum pralansia $(<45$ tahun). Pada penelitian ini umur dikategorikan produktif sebelum pralansia (15-44 tahun) dan produktif pralansia (45-59 tahun). Hal tersebut berarti penjamah makanan masuk dalam umur produktif dan belum memasuki kategori umur pralansia sehingga diharapkan mampu melaksanakan tugasnya dengan optimal.

Pendidikan Terakhir. Pada Tabel 1 menunjukkan bahwa sebagian besar pendidikan yang telah ditempuh penjamah makanan adalah SD. Hal ini dikarenakan tidak ada kualifikasi pendidikan penjamah makanan pada kedua penyelenggaraan makanan asrama putri tersebut.

Lama Bekerja. Berdasarkan hasil penelitian didapatkan sebagian besar penjamah makanan telah bekerja $\geq 3$ tahun. Menurut Faidzin dan Winarsih (2008), lama masa kerja merupakan pengalaman individu yang dapat menentukan perkembangan dalam pekerjaan.

\section{Keikutsertaan Pelatihan/Penyuluhan}

Berdasarkan Tabel 1 diperoleh sebagian besar penjamah makanan tidak pernah mengikuti pelatihan/penyuluhan mengenai higiene dan sanitasi penyelenggaraan makanan. Hal ini dikarenakan keterbatasan waktu dan biaya pada pihak penyelenggaraan makanan untuk mengadakan pelatihan/penyuluhan. Menurut Permenkes RI No.1096/ MENKES/PER/VI/2011, salah satu syarat tenaga penjamah makanan, yaitu memiliki sertifikat kursus higiene dan sanitasi makanan.

\section{Pengetahuan, Sikap dan Higiene Perorangan (Personal Hygiene)}

Hasil penelitian menunjukkan bahwa sebagian besar penjamah makanan mempunyai pengetahuan dan sikap yang baik mengenai higiene dan sanitasi penyelenggaraan makanan serta higiene perorangan (personal hygiene) yang masuk dalam kategori sedang. Pengetahuan dan sikap mengenai higiene dan sanitasi penyelenggaraan makanan serta higiene perorangan (personal hygiene) penjamah makanan dapat dilihat pada Tabel 2.

Pengetahuan. Pengetahuan pada penelitian ini merupakan pengetahuan penjamah makanan mengenai higiene dan sanitasi penyelenggaraan makanan. Pada Tabel 2 menunjukkan bahwa sebagian besar pengetahuan penjamah makanan masuk dalam kategori baik. Hal ini disebabkan karena berbagai faktor seperti pengalaman kerja, pekerjaan dan mendapatkan informasi dari berbagai tempat dan media.

Hasil penelitian ini sejalan dengan hasil penelitian Meikawati dkk., (2010), yang menyatakan sebagian besar penjamah makanan memiliki pengetahuan yang baik mengenai higiene dan sanitasi makanan (50,0\%).

Begitu pula dengan hasil penelitian Triandini dan Handajani (2015), yang menyatakan bahwa sebagian besar pengetahuan penjamah makanan mengenai higiene masuk dalam kategori baik sekali $(73,3 \%)$.

Sikap. Sikap penjamah makanan merupakan hasil penilaian penjamah makanan terhadap perilaku higiene dan sanitasi penyelenggaraan 
Tabel 1. Distribusi Karakteristik Penjamah Makanan

\begin{tabular}{lrr}
\hline \multirow{2}{*}{ Karakteristik Penjamah Makanan } & \multicolumn{2}{c}{ Jumlah $(\mathbf{n}=\mathbf{2 0})$} \\
\cline { 2 - 3 } & $\mathbf{n}$ & $\mathbf{\%}$ \\
\hline Umur & & \\
$\quad$ Produktif Sebelum Pralansia & 13 & 65,0 \\
$\quad$ Produktif Pralansia & 7 & 35,0 \\
\hline Pendidikan Terakhir & & \\
$\quad$ SD & 10 & 50,0 \\
SMP & 5 & 25,0 \\
$\quad$ SMA/SMK & 5 & 25,0 \\
$\quad$ Sarjana/Diploma & 0 & 0,0 \\
\hline Lama Bekerja (Tahun) & & \\
$\quad<3$ & 6 & 30,0 \\
$\quad \geq 3$ & 14 & 70,0 \\
\hline Keikutsertaan Pelatihan/ & & \\
Penyuluhan & & \\
$\quad$ Tidak Pernah & & \\
$\quad<3$ kali & 13 & 65,0 \\
$\quad$ 3 kali & 7 & 35,0 \\
& 0 & 0,0 \\
\hline
\end{tabular}

Tabel 2. Distribusi Pengetahuan, Sikap dan Higiene Perorangan (Personal Hygiene) Penjamah Makanan

\begin{tabular}{lrr}
\hline \multirow{2}{*}{ Kategori } & \multicolumn{2}{c}{ Jumlah $(\mathbf{n}=\mathbf{2 0})$} \\
\cline { 2 - 3 } & \multicolumn{1}{c}{$\mathbf{n}$} & $\mathbf{\%}$ \\
\hline Pengetahuan & & \\
$\quad$ Baik & 11 & 55,0 \\
Sedang & 4 & 20,0 \\
$\quad$ Kurang & 5 & 25,0 \\
\hline Sikap & & \\
$\quad$ Baik Sekali & 1 & 5,0 \\
Baik & 13 & 65,0 \\
Cukup & 6 & 30,0 \\
$\quad$ Kurang & 0 & 0,0 \\
\hline Higiene Perorangan & & \\
$\quad$ Baik & 0 & 0,0 \\
Sedang & 17 & 85,0 \\
$\quad$ Kurang & 3 & 15,0 \\
\hline
\end{tabular}

makanan. Berdasarkan Tabel 2 diperoleh sebagian besar sikap penjamah makanan masuk dalam kategori baik. Hal ini dapat disebabkan karena faktor pengalaman.

Menurut Azwar (2010), faktor yang memengaruhi sikap, yaitu pengalaman pribadi, pengalaman orang lain yang dianggap penting, pengaruh kebudayaan, media massa, lembaga pendidikan dan lembaga agama serta faktor emosional. Hasil penelitian ini sejalan dengan hasil penelitian Triandini dan Handajani (2015), sebagian besar penjamah makanan produksi otak- otak bandeng di Kabupaten Gresik memiliki sikap yang baik $(53,3 \%)$. Begitupula dengan hasil penelitian Meikawati dkk., (2010), yang menyatakan sikap penjamah makanan mengenai higiene dan sanitasi makanan yang tidak bersikap mendukung sebesar $50,0 \%$.

\section{Higiene Perorangan (Personal Hygiene)}

Higiene perorangan (personal hygiene) penjamah makanan merupakan perilaku hidup bersih dan sehat penjamah makanan selama penyelenggaraan makanan. Pada Tabel 2 menunjukkan bahwa sebagian besar higiene perorangan penjamah makanan masuk dalam kategori sedang. Hal ini disebabkan karena penjamah makanan tidak memakai alat pelindung diri dengan lengkap, tidak mencuci tangan dengan sabun sebelum dan sesudah memegang bahan makanan serta tidak tersedianya fasilitas sabun untuk mencuci tangan dan masker.

Hasil penelitian ini sejalan dengan hasil penelitian Erruliya (2008), yang menyatakan bahwa sebagian besar praktek higiene dan sanitasi penjamah makanan tergolong sedang $(66,7 \%)$. Praktek higiene dan sanitasi makanan dapat menentukan kualitas hygiene dan sanitasi makanan yang didukung dengan fasilitas yang memadai. Begitu pula dengan hasil penelitian Handayani dkk., (2015), yang menyatakan penjamah makanan masih melakukan perilaku berisiko saat mengolah makanan, seperti tidak menggunakan masker, penutup kepala, sarung tangan, banyak berbicara, menggaruk anggota tubuh dan mengunyah makanan saat sedang mengolah makanan. Perilaku tersebut dapat memperbesar kemungkinan terjadinya kontaminasi pada makanan yang diproduksi. Sedangkan menurut Permenkes RI No. 1096/ MENKES/PER/ $\mathrm{VI} / 2011$, penjamah makanan guna melindungi pencemaran terhadap makanan harus menggunakan celemek, penutup rambut dan sepatu kedap air serta menjaga perilaku selama bekerja seperti tidak banyak berbicara, selalu menutup mulut saat bersin atau batuk dan mencuci tangan sebelum dan setelah bekerja serta setelah keluar dari toilet/ kamar mandi. 


\section{Hubungan Pengetahuan dengan Sikap}

Pada hasil uji statistik menyatakan bahwa tidak ada hubungan antara pengetahuan dengan sikap penjamah makanan mengenai higiene dan sanitasi penyelenggaraan makanan. Hubungan antara pengetahuan dan sikap penjamah makanan dapat dilihat pada Tabel 3 .

Pada Tabel 3 menunjukkan pengetahuan penjamah makanan dengan kategori baik mempunyai sikap yang baik juga, yaitu sebesar $81,8 \%$. Namun, berdasarkan hasil uji statistik didapatkan $p$-value sebesar $0,60(\mathrm{p}>0,10)$ dan $\mathrm{r}=0,126$ yang berarti tidak ada hubungan antara pengetahuan dengan sikap penjamah makanan serta koefisien korelasi $\mathrm{r}$ menunjukkan bahwa korelasi antara kedua variabel sangat lemah. Hal tersebut dapat disebabkan karena terdapat faktor lain selain pengetahuan yang dapat memengaruhi sikap penjamah makanan, seperti sosial budaya, keyakinan dan pengalaman. Hal ini sejalan dengan Azwar (2010), yang menyatakan sikap individu terbentuk dari adanya interaksi sosial, berbagai faktor yang dapat memengaruhi sikap individu adalah pengalaman pribadi dan orang lain, kebudayaan serta emosi saat mengambil keputusan dalam menentukan sikap.

Hasil penelitian ini tidak sejalan dengan penelitian Erruliya (2008), yang menyatakan terdapat hubungan yang signifikan antara pengetahuan dengan sikap penjamah makanan tentang higiene dan sanitasi. Begitu pula dengan hasil penelitian Mangunsong dkk., (2015), yang menyatakan terdapat hubungan yang positif antara pengetahuan dengan sikap siswa dalam melaksanakan higiene dan sanitasi pada praktek pengolahan kue.

Namun, pada hasil penelitian, penjamah makanan dengan pengetahuan baik memiliki sikap yang baik, yaitu sebesar 81,8\% dibandingkan dengan pengetahuan penjamah makanan kategori baik yang memiliki sikap kategori cukup, yaitu sebesar $9,1 \%$. Hal ini menunjukkan terdapat kecenderungan bahwa penjamah makanan dengan sikap baik mempunyai pengetahuan mengenai higiene dan sanitasi penyelenggaraan makanan yang baik pula, meskipun tidak cukup kuat untuk menunjukkan terdapat hubungan antara pengetahuan dan sikap. Berdasarkan hasil penelitian Handayani dkk., (2015), menyatakan bahwa penjamah makanan yang memiliki sikap baik cenderung memiliki pengetahuan yang baik.

Demikian juga menurut Mangunsong dkk., (2015), semakin baik pengetahuan higiene dan sanitasi, semakin baik pula sikap siswa dalam melaksanakan praktek higiene dan sanitasi pada praktek mengolah kue.

\section{Hubungan Pengetahuan dengan Higiene Perorangan (Personal Hygiene)}

Menurut hasil uji statistik terdapat hubungan antara pengetahuan dengan higiene perorangan (personal hygiene) penjamah makanan. Hubungan antara pengetahuan dengan higiene perorangan (personal hygiene) dapat dilihat pada Tabel 4.

Pada Tabel 4 menunjukkan bahwa pengetahuan penjamah makanan yang baik memiliki perilaku kebersihan diri atau higiene perorangan kategori sedang, yaitu sebesar 100,0\%. Berdasarkan hasil uji statistik menunjukkan bahwa ada hubungan yang signifikan antara pengetahuan dengan higiene perorangan (personal hygiene) penjamah makanan, di mana $p$-value sebesar $0,08(\mathrm{p}<0,10)$ dan $r=0,404$. Korelasi antara kedua variabel tersebut cukup kuat. Hal tersebut menunjukkan bahwa salah satu faktor yang dapat memengaruhi perilaku higiene perorangan penjamah makanan adalah pengetahuan. Hal ini sejalan dengan hasil penelitian Avrilinda dan Kristiastuti (2016), yang

Tabel 3. Distribusi Pengetahuan dan Sikap

\begin{tabular}{|c|c|c|c|c|c|c|c|c|c|c|c|c|}
\hline \multirow{3}{*}{ Pengetahuan } & \multicolumn{8}{|c|}{ Sikap } & \multirow{2}{*}{\multicolumn{2}{|c|}{ Total }} & \multirow{3}{*}{ p-value } & \multirow{3}{*}{$\begin{array}{c}\text { Koefisien Korelasi } \\
\mathbf{r}\end{array}$} \\
\hline & \multicolumn{2}{|c|}{ Baik Sekali } & \multicolumn{2}{|c|}{ Baik } & \multicolumn{2}{|c|}{ Cukup } & \multicolumn{2}{|c|}{ Kurang } & & & & \\
\hline & $\mathrm{n}$ & $\%$ & n & $\%$ & $\mathrm{n}$ & $\%$ & $\mathrm{n}$ & $\%$ & n & $\%$ & & \\
\hline Baik & 1 & 9,1 & 9 & 81,8 & 1 & 9,1 & 0 & 0,0 & 11 & 100,0 & & \\
\hline Sedang & 0 & 0,0 & 1 & 25,0 & 3 & 75,0 & 0 & 0,0 & 4 & 100,0 & 0,600 & 0,126 \\
\hline Kurang & 0 & 0,0 & 3 & 60,0 & 2 & 40,0 & 0 & 0,0 & 5 & 100,0 & & \\
\hline
\end{tabular}


Tabel 4. Distribusi Pengetahuan dan Higiene Perorangan (Personal Hygiene)

\begin{tabular}{|c|c|c|c|c|c|c|c|c|c|c|}
\hline \multirow{3}{*}{ Pengetahuan } & \multicolumn{6}{|c|}{ Higiene Perorangan (Personal Hygiene) } & \multirow{2}{*}{\multicolumn{2}{|c|}{ Total }} & \multirow{3}{*}{ p-value } & \multirow{3}{*}{ Koefisien korelasi $r$} \\
\hline & \multicolumn{2}{|c|}{ Baik } & \multicolumn{2}{|c|}{ Sedang } & \multicolumn{2}{|c|}{ Kurang } & & & & \\
\hline & $\mathbf{n}$ & $\%$ & $\mathrm{n}$ & $\%$ & $\mathbf{n}$ & $\%$ & n & $\%$ & & \\
\hline Baik & 0 & 0,0 & 11 & 100,0 & 0 & 0,0 & 11 & 100,0 & & \\
\hline Sedang & 0 & 0,0 & 3 & 75,0 & 1 & 25,0 & 4 & 100,0 & 0.080 & 0,404 \\
\hline Kurang & 0 & 0,0 & 3 & 60,0 & 2 & 40,0 & 5 & 100,0 & & \\
\hline
\end{tabular}

menyatakan pengetahuan berpengaruh terhadap perilaku higiene penjamah makanan.

Demikian juga hasil penelitian Erruliya (2008), yang menyatakan bahwa terdapat korelasi yang positif antara pengetahuan dengan perilaku. Pengetahuan penjamah makanan yang baik mendukung sikap positif agar dapat menerapkan prinsip higiene dan sanitasi penyelenggaraan makanan dengan baik dan benar. Hasil penelitian Sanlier dan Konaklioglu (2012), juga menyatakan bahwa terdapat korelasi yang kuat antara pengetahuan keamanan pangan dengan perilaku penjamah makanan $(\mathrm{r}=0,406 . p<0,01)$.

\section{KESIMPULAN DAN SARAN}

Kesimpulan dari penelitian ini diketahui bahwa pengetahuan tidak berhubungan dengan sikap penjamah makanan, namun pengetahuan berhubungan dengan higiene perorangan (personal hygiene) penjamah makanan.

Hasil penelitian ini dapat dijadikan sebagai bahan evaluasi bagi pengelola penyelenggaraan makanan untuk lebih memperhatikan higiene dan sanitasi penyelenggaraan makanan dengan cara meningkatkan pengawasan. Cara yang dapat dilakukan adalah dengan mengadakan inspeksi mendadak seminggu sekali yang dilakukan oleh pengelola penyelenggaraan makanan atau kepala Yayasan Islamic Boarding School dan menambahkan fasilitas yang dapat menunjang perilaku higiene perorangan penjamah makanan seperti menyediakan sabun untuk mencuci tangan dan menyediakan masker. Penyelenggaraan makanan asrama putri perlu memberikan pelatihan mengenai higiene dan sanitasi makanan kepada penjamah makanan agar sesuai dengan Permenkes RI No. 1096 /MENKES/PER/VI/2011.

\section{DAFTAR PUSTAKA}

Avrilinda, S. M. dan Kristiastuti, D. (2016). Pengaruh pengetahuan dan sikap terhadap perilaku higiene penjamah makanan di kantin SMA Muhammadiyah 2 Surabaya. e-journal Boga, 5(2), 1-7. Diakses dari http://ejournal. unesa.ac.id.

Azwar, S. (2010). Sikap manusia: Teori dan pengukurannya. Yogyakarta: Pustaka Pelajar.

Badan POM R.I. (2011). Laporan Tahunan 2011 Badan Pengawasan Obat dan Makanan. Jakarta: Badan Pengawasan Obat dan Makanan RI. Diakses dari http://www.pom.go.id/ppid/rar/ LAPTAH_2011.pdf.

Budiyono., Junaedi, H., Isnawati., Wahyyuningsih, T. (2008). Tingkat pengetahuan dan praktik penjamah makanan di Tembalang Kota Semarang Tahun 2008. Jurnal Promosi Kesehatan Indonesia, 4(1), 50-60. Diakses dari http:// ejournal.undip.ac.id/index.php/jpki/article/ view/2411.

Cahyaningsih, C.T., Kushadiwijaya, H., Tholib, A. (2009). Hubungan higiene sanitasi dan perilaku penjamah makanan dengan kualitas bakteriologis peralatan makanan di warung makan. Berita Kedokteran Masyarakat, 25(4),180-188. Diakses dari http://beritakedokteran-masyarakat.org

Erruliya. (2008). Faktor yang mempengaruhi praktek hygiene dan sanitasi penjamah makanan pada usaha jasaboga Dharma Wanita RSU Dr. Soedono Madiun (Skripsi tidak diterbitkan). Universitas Airlangga, Surabaya.

Faidzin, A., dan Winarsih., (2008). Hubungan tingkat pendidikan dan lama kerja perawat dengan kinerja perawat di RSU Pandan Arang Kabupaten Boyolali. Berita Ilmu Keperawatan ISSN 2979-2697, 1(3), 137-142. Diakses dari http://www.infodiknas.com/wp-content/ uploads/2014/11. 
Fatmawati, S., Rosidi, A., Handasari, E. (2013). Perilaku higiene pengolah makanan berdasarkan pengetahuan tentang higiene mengolah makanan dalam penyelenggaraan makanan di Pusat Pendidikan dan Latihan Olahraga Pelajar Jawa Tengah. Jurnal Gizi Universitas Muhammadiyah Semarang, 2(2), 30-38. Diakses dari http:// jurnal.unimus.ac.id.

Handayani, N.M.A., Adhi, K.T., Duarsa, D.P. (2015). Faktor yang mempengaruhi perilaku penjamah makanan dalam penerapan cara pengolahan pangan yang baik pada industri rumah tangga di Kabupaten Karangasem. Public Health and Preventive Medicine Archive,3(2), 194-202. Diakses dari http://ojs.unud.ac.id/index.php/ phpma/article/download/19697/13082.

Kemenkes RI. (2011). Peraturan Menteri Kesehatan RINomor 1096/MENKES/PER/VI/2011 tentang higiene sanitasi jasaboga. Direktorat Gizi Masyarakat. Jakarta: Kementerian Kesehatan RI.

Mangunsong, S. W. A., Yusuf, L., Syarif, W. (2015). Hubungan pengetahuan hygiene sanitasi dengan sikap siswa pada praktek mengolah kue indonesia di Workshop SMKN 3 Muara Bungo.
E-Journal Home Economic and Tourism, 8(1), 1-16. Diakses dari http://ejournal.unp.ac.id/ index.php/jhet/article/view/4532/3579.

Meikawati, W., Astuti., Susilawati. (2010). Hubungan pengetahuan dan sikap petugas penjamah makanan di Unit Gizi RSJD Dr. Amino Gondohutomo Semarang. Jurnal Kesehatan Masyarakat Indonesia, 6(2), 50-68. Diakses dari http://jurnal.unimus.ac.id./index. php.jkmi/article/view/154/136.

Purwaningtyas, S. (2013). Gambaran penyelenggaraan makan di Pondok Pesantren AlQodiri Kabupaten Jember (Skripsi Universitas Jember, Jember). Diakses dari http://repository. unej.ac.id.

Sanlier, N., and Konaklioglu, E. (2012). Food safety knowledge, attitude and food handling practices of students. British Food Journal, 114(4), 469480. Diakses dari http://emeraldinsight.com.

Triandini, F.A., dan Handajani, S. (2015). Pengetahuan, sikap penjamah makanan dan kondisi higiene sanitasi produksi otak-otak bandeng di Kabupaten Gresik. E-Journal Boga, 04(2), 27-36. Diakses dari http://ejournal.unesa. ac.id. 